\title{
RESIDÊNCIA DE ENFERMAGEM: UMA TRAJETÓRIA DE 20 ANOS
}

\author{
NURSING RESIDENCY: 20 YEARS OF EXPERIENCE \\ PRÁCTICAS DE ENFERMERIA: UNATRAYECTORIA DE 20 AÑOS
}

\author{
Antonia da Conceiçăo Cylindro' \\ Sonia Regina de Oliveira e Silva de Souza ${ }^{2}$ \\ Luciana Guimarães Assad ${ }^{3}$ \\ Maria Virginia Godoy da Silva ${ }^{4}$
}

\begin{abstract}
RESUMO: Estudo descritivo sobre a trajetória da Residência de Enfermagem do HUPE no periodo entre 1978 e 1998. Descreve as evoluçōes ocorridas na Residência em termos da organização dos programas, atividades teóricas, pesquisa, preceptoria, avaliaçăo e perspectivas para o futuro. $O$ estudo se deu a partir de uma abordagem qualitativa. A coleta de dados utilizou a técnica da Análise Documental. Os documentos analisados constituíram-se em livros, fluxogramas de estágio, atas de reunião entre outros. As crenças e tendências atuais do ensino têm encaminhado a construção dos programas da Residência para um trabalho conjunto entre residentes e preceptores. Valoriza-se a residência enquanto estratégia para a especialização de enfermeiros.
\end{abstract}

PALAVRAS-CHAVE: residência, enfermagem

\section{INTRODUÇÄO}

A Residência de Enfermagem é parte do cotidiano do Hospital Universitário Pedro Ernesto (HUPE), instituição vinculada à Universidade do Estado do Rio de Janeiro (UERJ). Atualmente, está organizada em doze Programas diferentes a saber: Adolescentes, Clínica, Cirúrgica, Centro Cirúrgico, Cirurgia Cardiovascular, Nefrologia, Obstetricia, Pediatria, Psiquiatria, Saúde Coletiva, Terapia Intensiva e Unidade Coronariana (Anexo 1). Todos os programas têm a duração de dois anos, totalizando a carga horária anual de $\mathbf{2 8 8 3}$ horas, distribuídas em atividades de treinamento em serviço, teóricas e de pesquisa. São oferecidas cinqüenta vagas para o total de programas. Assim, entre os residentes do primeiro e segundo ano, forma-se um grupo de 100 enfermeiros. Este estudo busca apresentar a caminhada da Residência de Enfermagem do HUPE nestes últimos vinte anos, correspondendo ao periodo de 1978 a 1998.

A Residência de Enfermagem, segundo Lima (1979), teve início no Brasil em 1961, no Hospital Infantil do Morumbi. São Paulo. Lima (1979), Alcoforado (1978) e Novaes (1978) ressaltam a importância da Residência como projeto de especialização e aperfeiçoamento pois estimula o desenvolvimento profissional, qualifica as ações e torna a assistência eficiente para o paciente,

\footnotetext{
' Enfermeira do Serviço de Treinamento e Avaliação de Enfermagem do HUPE/UERJ Professora Assistente da Faculdade de Enfermagem da UNIGRANRIO. Mestre em Enfermagem.

${ }^{2}$ Enfermeira do Serviço de Treinamento e Avaliação de Enfermagem do HUPE/UERJ. Mestre em Enfermagem. Professora Assistente do Departamento de Enfermagem Médico Cirúrgica da FEUERJ

${ }^{3}$ Enfermeira do Serviço de Treinamento e Avaliação de Enfermagem do HUPE/UERJ. Mestre em Enfermagem. Rua Gilberto Cardoso, 280/604. Rio de Janeiro. CEP: 22.430-070

${ }^{4}$ Enfermeira responsável pelo Serviço de Treinamento e Avaliaçäo de Enfermagem do HUPE/ UERJ. Mestre em Enfermagem. Professora Assistente do Departamento de Enfermagem Médico Cirúrgica da FEUERJ.
} 
familia e comunidade. Os autores acima citados destacam como pontos positivos da Residência a melhora na qualidade na assistência, a complementação do aprendizado e como negativos a exploração do recém formado e o não reconhecimento do titulo quando não há a participação de uma escola de enfermagem. Nesta pesquisa, defende-se a idéia da Residência de Enfermagem como uma proposta válida para a especialização de enfermeiros, requerendo as devidas adaptações face às necessidades do mercado de trabalho, dos serviços e das novas tendências curriculares, somadas à experiência de 20 anos.

\section{OBJETIVOS}

Este estudo tem como objetivos:

- Apresentar a evolução da Residência de Enfermagem do HUPE/UERJ no periodo compreendido entre 1978 e 1998 ;

- Analisar as modificações ocorridas nos diversos programas da Residência;

- Oferecer subsidios para instituiçōes que desejam oferecer ou ofereçam programas de Residência de Enfermagem.

\section{DESENVOLVIMENTO}

Trata-se de um estudo descritivo, realizado em um hospital universitário de grande porte e que relata a experiência vivida nesta instituição com Residência de Enfermagem. A coleta de dados se deu mediante a técnica da Análise Documental de trabalhos já realizados por enfermeiros sobre este tema. Os documentos analisados constituiram-se em livros, fluxogramas de estágio, atas de reunião e todo tipo de documento arquivado na atual Coordenação da Residência de Enfermagem. Teve-se grande dificuldade para obter dados referentes aos primeiros anos da Residência. Somente a partir do ano de 1988 que se começou a encontrar registros sistematizados, compreensiveis e, assim sendo, passiveis de análise. Esta análise deu-se a partir de uma abordagem qualitativa. Apresentam-se crenças, experiências, tentativas de ensaio e erro, além de opiniōes do grupo de enfermeiros que atualmente respondem pela operacionalização da Residência de Enfermagem, na instância da Coordenação de todos os programas de Residência. A análise se deu a partir de categorias que contemplam diferentes componentes dos programas de Residência e incluiu: organização dos programas, atividades teóricas, atividades de pesquisa. preceptoria, avaliação e perspectivas para o futuro.

\section{ORGANIZAÇÃO DOS PROGRAMAS}

Conforme explicado anteriormente, as informações sobre os primeiros anos de residência , mais precisamente os dez primeiros anos não se encontravam arquivadas de forma que pudessem ser analisadas. Houve destruição e/ou desaparecimento de grande parte deste material, o que prejudicou bastante esta análise. Sabe-se da organização dos primeiros programas porque os integrantes destas turmas de residentes, hoje, integram o corpo de enfermeiros do mesmo hospital. Inicialmente, os programas tinham a duração de um ano somente e contemplavam áreas como a Enfermagem Médico Cirúrgica, a Nefrologia e Materno Infantil. A partir do ano de 1987, estendeu-se a duração dos programas para dois anos e, em 1988, aconteceu a primeira turma de residentes cursando o segundo ano, e que passaram a ser denominados R2. Segundo informações de ex-residentes, hoje enfermeiros do hospital e através de atas de reuniões de avaliaçōes anuais daquela época, a expansão dos programas para dois anos foi uma conquista desse grupo, contando naturalmente com o apoio e intervenção do então Chefe da Divisão de Enfermagem do HUPE.

Após a expansão de todos os programas para dois anos, pôde-se constatar duas fortes 
tendências para a organização e estruturação dos programas: a super especialização e a generalização. Assim, durante alguns anos foram oferecidos programas como a Enfermagem Médico Cirúrgica, a Administração, Enfermagem em Doenças Infecto Parasitárias. Já há quase seis anos, os programas são mantidos e pequenos ajustes são realizados. Entende-se que já existe um consenso entre as características próprias do hospital, as demandas do mercado de trabalho, bem como o respeito e reconhecimento a determinadas especialidades e áreas do conhecimento da Enfermagem. Cabem, como exemplo, a Terapia Intensiva, Nefrologia, Centro Cirúrgico, Pediatria entre outras. Para outros programas, projetos da própria universidade fazem com que sejam mantidos, bem como asa idéias e propostas que representam. Nesta situação, se enquadram o Programa de Adolescentes, e da Saúde da Familia (sendo este inserido como unidade de treinamento do Programa de Saúde Coletiva).

A partir do ano de 1992, optou-se pela realização anual de reuniões entre residentes do primeiro e segundo ano, preceptores e enfermeiros que integram a Coordenação da Residência de Enfermagem para, juntos, avaliarem e proporem as unidades de treinamento dos programas a serem oferecidos nos dois próximos anos. Desta forma, avalia-se a permanência de uma dada unidade em determinado programa ouvindo opiniões dos mais diferentes sujeitos. Os residentes podem opinar sobre as situaçōes de aprendizagem, composição da equipe e até mesmo a organização da unidade em termos da planta fisica e recursos materiais. Os enfermeiros preceptores também opinam sobre o tempo de permanência de cada residente, a característica da própria unidade e a sua conveniência para os residentes R1 e R2. Desta forma, definem-se as unidades de treinamento, o periodo de cada uma e busca-se, ainda, conciliar necessidades do serviço e necessidades dos próprios enfermeiros residentes (que no segundo ano escolhem seu mês de férias). Em seguida, são elaborados os fluxogramas onde ficam determinados, nomes, meses e unidades para todos os residentes em todos os programas.

\section{ATIVIDADES TEÓRICAS}

Ao longo destes 20 anos, as atividades teóricas da Residência foram representadas por aulas expositivas ministradas pelos enfermeiros preceptores, pelos próprios residentes, por docentes da Faculdade de Enfermagem da UERJ, além de convidados especiais de outras instituições. A análise documental revelou que se tratava de uma prática a principio assistemática, passando, a seguir, a constituir-se em uma tentativa de conteúdo programático. Quanto à forma de oferecimento destes conteúdos, durante alguns anos, se dava em um momento único, por ocasião da chegada dos residentes, e sua duração se estendia aos 3 primeiros meses de residência. Os conteưdos abrangiam áreas como a Administração em Enfermagem. Assistência de Enfermagem em Situaçōes de Emergência, além de assuntos como Insuficiência Renal, Diabetes, entre outras. Havia programas que solicitavam, aos residentes, a elaboração de um estudo de caso, resultado da sua vivência e trabalho junto a um cliente em especial. Esta experiência era apresentada para outros residentes e preceptores. Torna-se importante destacar que houve um periodo de tempo, não inferior a 3 anos, quando praticamente não se encontrou registro relativo ao desenvolvimento de conteúdo teórico. Razões como falta de tempo, a necessidade premente de permanência do residente na unidade. foram protelando um envolvimento do grupo como um todo, deixando a teoria praticamente no esquecimento. Os residentes acabavam sendo compensados obtendo "liberaçōes programadas" para eventos cientificos realizados no municipio do Rio de Janeiro e até mesmo em outras cidades, numa tentativa de compensar a teoria devida. Cabe destacar que, nestes últimos dez anos, ficou estabelecida a proporção de $20 \%$ para atividades teóricas e $80 \%$ para treinamento em serviço. Deseja-se ainda registrar o "caminhar" de preceptores e residentes do Programa de Pediatria que vieram se organizando já há algum tempo, tendo operacionalizado um programa teórico de duração anual, independente, coerente com as necessidades especificas e que, até mesmo, 
motivou iniciativa semelhante em outras áreas. Atualmente, o programa teórico está sendo oferecido de outra maneira, em uma nova tentativa. Cada programa tem suas atividades especificas e além disso foram organizados conteúdos gerais para os residentes do primeiro e segundo ano.

As justificativas para a atual proposta se baseiam no desejo de oferecer conteúdos que atendam as mais diversas especialidades, além daqueles entendidos como importantes para a formação do enfermeiro independente de sua área de atuação. Além disso, busca-se permitir o encontro destes jovens residentes, muitas vezes tão próximos e tão distantes em um grande hospital.

\section{ATIVIDADES DE PESQUISA}

As atividades de pesquisa na Residência de Enfermagem do HUPE/UERJ têm sido, até o momento, o espaço onde se evidencia a grande parceria entre a FEUERJ e o Hospital Universitário Pedro Ernesto. Após o ingresso dos docentes, formalmente a partir do ano de 1991 através do Projeto intitulado "Implementação do Curso de Metodologia da Pesquisa em Enfermagem para Residentes de Enfermagem do HUPE", deu-se a organização dos conteúdos teóricos sobre metodologia científica, definição dos orientadores e conseqüentemente um salto na qualidade nos trabalhos apresentados. Deseja-se destacar que, nesta época, face ao número reduzido de professores orientadores (eram somente duas) para um grande número de residentes (cinqüenta), havia uma composição heterogênea dos grupos, o que gerava, muitas vezes, "distorções" do tipo residentes concluindo um programa de Enfermagem em Centro Cirúrgico e com um trabalho sobre Estimulação Essencial em Neonatologia. A segunda tentativa de trabalho conjunto com a FEUERJ se deu após o ingresso de uma nova professora, em substituição as duas pioneiras, e que trouxe como inovação a parceria com enfermeiros do hospital universitário. que passaram a atuar como co-orientadores, permitindo assim que os residentes pudessem desenvolver trabalhos na sua área de especialização. Desta época para os dias atuais, formalizouse, no calendário de eventos científicos do HUPE, os chamados "Seminários de Pesquisa dos Residentes de Enfermagem", que acontecem anualmente no mês de fevereiro, quando os residentes $\mathrm{R} 1$ apresentam seus projetos de pesquisa e os residentes $\mathrm{R} 2$ os relatórios de pesquisa. Esta professora afastou-se também do projeto para realizar o doutorado, mas as atividades de pesquisa estão consolidadas. Paralelamente, multiplicou-se o número de orientadores, representados por enfermeiros docentes da FEUERJ e assistenciais do HUPE que, em parceria, vêm construindo e fortalecendo as linhas de pesquisa como a "Enfermagem Assistencial", além de correntes metodológicas e abordagens filosóficas como as Representações Sociais, a Dialética, a Pesquisa Participante entre outros.

\section{PRECEPTORIA}

Para este estudo, e com base na realidade vivida no Hospital Pedro Ernesto, entende-se preceptor como todo enfermeiro que atua em unidade onde se desenvolve em Programa da Residência. A trajetória da Residência de Enfermagem evidencia um crescente expansão do papel do preceptor. Antigamente, era somente aquele enfermeiro chefe de unidade que se ocupava ou era mesmo responsabilizado pelos residentes de enfermagem. Hoje, conta-se com um grande número de parceiros preceptores que atuam como orientadores no treinamento em serviço, trabalhos de pesquisa e expositores nas atividades teóricas. Cabe destacar que o Programa de Educação Continuada implementado nas últimas gestões da Coordenadoria de Enfermagem tem incentivado a facilitado a participação de enfermeiros em Cursos de Pós Graduação scrictu e lato sensu, ampliando os horizontes destes profissionais. Novos mestres, doutorandos e mestrandos engajam-se com uma nova visão nos programas da Residência, 
renovando-os, bem como a instituição como um todo.

Em fevereiro próximo passado, realizou-se o Seminário de Preceptoria e seus resultados indicaram que já se percebe a preceptoria imbricada com as relações de autoridade e poder. Os preceptores atuais queixam-se de suas atividades múltiplas e sentem-se ainda com poucos conhecimentos sobre a docência e insatisfeitos por não receberem nenhuma remuneração especifica pelo exercicio da preceptoria. Em função desta necessidade sentida, está sendo oferecido aos enfermeiros do HUPE um Curso de Metodologia do Ensino Superior em parceria com a Faculdade de Educação da UERJ.

\section{AVALIAÇÃO}

A avaliação dos residentes de Enfermagem representa um dos maiores desafios ainda hoje na prática da Residência de Enfermagem. Kestemberg (1996) analisa o ato avaliativo de uma forma ampla e imbricado num cenário sócio-politico-cultural. A mesma autora considera ainda a avaliação como atividade política, visto que é também uma forma de expressar e interpretar as relações sociais. Neste momento, experimenta-se um novo instrumento de avaliação (Anexo 3), e que busca substituir o anterior considerado insuficiente e impróprio. Cabe destacar que o instrumento de avaliação reservou um espaço para que residentes e preceptores possam expressar-se por escrito, formalizando assim as razōes para os conceitos emitidos por ambos.

\section{PERSPECTIVAS PARA O FUTURO}

Neste estudo, relatou-se de forma sucinta, a experiência acumulada em 20 anos de Residência de Enfermagem. A crença de que a Residência é uma modalidade válida para a especialização de enfermeiros permanece. Participando de muitos eventos sobre este tema, percebe-se uma tendência nacional de caminhar buscando o seu reconhecimento e, muitas vezes, estabelecendo a parceria formal com escolas de enfermagem, titulando os residentes como especialistas. A preceptoria aparece como um elemento importantíssimo ao processo como um todo. A teoria e a pesquisa constituem-se em alicerces de importância indiscutivel. A Residência exige uma infra-estrutura pedagógica semelhante à de um curso de pós graduação: espaços fisicos como salas de aula, bibliotecas e recursos audiovisuais de toda a ordem. As unidades de treinamento devem estar preparadas para receber estes enfermeiros, recém formados na sua maioria, para serem preparados para o mercado de trabalho, buscando entendêlo em um contexto amplo, discutindo-o e transformando-o. Os profissionais das equipes que atuam com estes residentes também precisam estar envolvidos em um Programa de Educação Continuada Permanente para que possam e saibam como receber e trabalhar em conjunto com estes enfermeiros. Ás gerências responsáveis por estes programas, cabe o permanente desafio de conciliar os interesses da instituição aos dos residentes, combinando a força de trabalho que representam ao perigo desta mesma força ser utilizada de forma exploradora, inábil e desrespeitando a concepção origınal dos programas. Finalmente, valoriza-se a construção e avaliação conjunta dos programas pelos atores deste processo, no caso, preceptores e os próprios residentes.

\section{CONSIDERAÇÕES FINAIS}

Neste estudo, apresentou-se a trajetória da Residência de Enfermagem do Hospital Universitário Pedro Ernesto no periodo compreendido entre 1978 e 1998. Foram tratadas as modificações ocorridas na organização dos programas, atividades teóricas, de pesquisa, preceptoria e avaliação. Valoriza-se a residência enquanto estratégia para a especialização de 
enfermeiros. As crenças e tendências atuais do ensino têm encaminhado a construção dos programas da Residência para um trabalho conjunto entre residentes e preceptores. Algumas áreas do conhecimento da Enfermagem vêm se consolidando, ao longo destes anos, como a Terapia Intensiva, a Nefrologia. o Centro Cirúrgico e a Pediatria.

ABSTRACT: This descriptive study about Nursing Residence is an attempt to understand the period between 1978 and 1998. Describes the evolution occured on Residence about programs organization, theorical and research activities, preceptory, avaliation and future perspectives. The study has a Qualitative Approach. The data was collected with Documental Analysis. The actuals beliefs and tendencies are indicating that the residence programs must be constructed by Nursing Residents and Preceptors. The Nursing Residence is a valuable strategic of especialization of nurses at service.

KEYWORDS: residence, nursing

RESUMEN : Estudio descriptivo sobre la trayectoria de las Prácticas de Enfermeria del HUPE en el periodo entre 1978 y 1998. Describe la evolución ocurrida en las Prácticas respecto a la organización de los programas, actividades teóricas, investigación, preceptoria/enseñanza, evaluación y perpectivas para el futuro. El estudio se desarrolló, a partir de un punto de vista calitativo. Para la recogida de datos, se utilizo la técnica del Análisis Documental. La documentación analizada estaba constituida por libros, flujogramas de Stages, actas de reuniones, entre otros materiales. Las creencias y tendencias actuales de la enseñanza orientan la construcción de los programas de las Prácticas hacia un trabajo conjunto entre residentes y preceptores. Se valoriza la residencia/prácticas encuanto estrategia para la especialización de los enfermeros

PALABRAS CLAVE: prácticas, residencia, enfermeria

\section{REFERÊNCIAS BIBLIOGRÁFICAS}

ALCOFORADO, L.M.A. "A Residência de Enfermagem : um processo de ensino ou trabalho". Revista Bras. de Enf., n.31, p.340-345, 1978

KERSTENBERG, C. "Avaliação: O caos nosso de todo dia". Rio de Janeiro: Cultura Médica, 1996

LIMA, D.M. "Um estudo da Residência na área de Enfermagem". Rio de Janeiro, Dissertação (Mestrado). Escola de Enfermagem Anna Nery da Universidade Federal do Estado do Rio de Janeiro, 1979

NOVAES, D.P.I. et al "Residência em Enfermagem. Vantagens e Desvantagens". Revista Esc. Enf. USP. v.12, n.2, p. 101-108, 1978. 